\title{
Defining the expression of marker genes in equine mesenchymal stromal cells
}

\author{
Deborah J Guest ${ }^{1}$ \\ Jennifer C Ousey' \\ Matthew RW Smith ${ }^{2}$ \\ 'Animal Health Trust, Lanwades Park, \\ Kentford, Newmarket, Suffolk, CB8 \\ 7UU; ${ }^{2}$ Reynolds House Referrals, \\ Greenwood Ellis and Partners, 166 \\ High Street, Newmarket, Suffolk, CB8 \\ 9WS, UK
}

\begin{abstract}
Mesenchymal stromal (MS) cells have been derived from multiple sources in the horse including bone marrow, adipose tissue and umbilical cord blood. To date these cells have been investigated for their differentiation potential and are currently being used to treat damage to horse musculoskeletal tissues. However, no work has been done in horse MS cells to examine the expression profile of proteins and cell surface antigens that are expressed in human MS cells. The identification of such profiles in the horse will allow the comparison of putative MS cells isolated from different laboratories and different tissues. At present it is difficult to ascertain whether equivalent cells are being used in different reports. Here, we report on the expression of a range of markers used to define human MS cells. Using immunocytochemistry we show that horse MS cells homogenously express collagens, alkaline phosphatase activity, CD44, CD90 and CD29. In contrast, CD14, CD79 $\alpha$ and the embryonic stem cell markers Oct-4, SSEA (stage specific embryonic antigen) $-1,-3,-4$, TRA (tumor rejection antigen) -1-60 and -1-81 are not expressed. The MS cells also express MHC class I antigens but do not express class II antigens, although they are inducible by treatment with interferon gamma (IFN- $\gamma$ ).
\end{abstract}

Keywords: mesenchymal stem cells, equine, gene expression

\section{Introduction}

Mesenchymal stromal (MS) cells have been isolated from the bone marrow of mice (Pereira et al 1995; Prockop 1997) and human (Pittenger et al 1999) and can differentiate into multiple mesenchymal tissues. MS cells have also been derived in the horse from a variety of tissues including bone marrow (Vidal et al 2006; Arnhold et al 2007), adipose tissue (Vidal et al 2007), peripheral blood (Koerner et al 2006), umbilical cord blood (Koch et al 2007; Reed and Johnson 2008), and umbilical cord matrix (Hoynowski et al 2007). They are of particular interest in the horse for their potential to treat injuries to musculoskeletal tissues such as tendon (Smith et al 2003; Guest et al 2008) and cartilage (Wilke et al 2007).

Although there have been many reports on the isolation and in vitro differentiation of these cells, there are no published studies to specifically identify markers of horse MS cells and only limited investigations have been undertaken. Instead, researchers have used crude means of validation including the propensity of the cells to adhere to tissue culture plastic and their ability to differentiate into bone (Vidal et al 2006), cartilage (Hegewald et al 2004), and fat (Koch et al 2007). Although even these methods have produced some inconsistencies with some researchers reporting an inability to differentiate MS cells into fat cells (Koerner et al 2006; Reed and Johnson 2008).

In human research three criteria have been proposed for the identification of multipotent MS cells; their adherence to plastic, their multipotent differentiation potential and their specific surface antigen expression (Dominici et al 2006). As yet no single specific marker of MS cells exists in any species and thus a panel of cell surface antigens must be studied. Human MS cells are defined as being positive for 
CD105, CD73, and CD90 and negative for CD45, CD34, CD14, CD79 $\alpha$, and MHC class II antigens (Dominici et al 2006).

We examined the expression of these antigens in horse MS cells (where antibodies recognizing horse were commercially available) as well a selection of other genes previously studied in MS cells, including collagen type I (Pereira et al 1995), collagen type III (Beresford et al 1992), alkaline phosphatase activity (Vidal et al 2006), CD44 (Bosch et al 2006), CD29 (Chang et al 2006), and the embryonic stem (ES) cell gene SSEA-4 (Gang et al 2007), which have all been shown to be expressed in human MS cells. We also examined the expression of other ES cell genes including Oct-4, Tra-1-60, Tra-1-81, SSEA-3, and SSEA-1. All of these genes are expressed in horse ES cells (Guest and Allen 2007) and some are expressed in horse MS cells derived from umbilical cord blood and adipose tissue (Reed and Johnson 2008). From these studies we were able to define a profile of genes that are expressed in horse bone marrow and umbilical cord blood-derived MS cells that can now be compared to MS cells derived from other tissue sources and by other laboratories to identify common standards.

\section{Materials and methods}

\section{Bone marrow and umbilical cord blood collection, MS cell isolation and culture}

Two $10.5 \mathrm{ml}$ aliquots of bone marrow were collected from four Thoroughbred geldings aged 2-4 years as described previously (Smith et al 2003). Sixty-five to $115 \mathrm{ml}$ of umbilical cord blood was collected from six Thoroughbred foals at birth into heparin (Sigma, Gillingham, Dorset, UK) containing tubes. The horses were cared for in accordance with institutional guidelines and work was performed with ethical approval and under Home Office licence. Whole cord blood or bone marrow was centrifuged through histopaque (Sigma). The buffy layer of mononuclear cells was collected and washed in culture medium (DMEM supplemented with $10 \%$ fetal calf serum, $2 \mathrm{mM}$ L-glutamine, $100 \mathrm{U} / \mathrm{ml}$ penicillin and $100 \mu \mathrm{g} / \mathrm{ml}$ streptomycin [all from Invitrogen, Paisley, UK]) before plating all the cells at high density in $10 \mathrm{ml}$ medium onto a $10 \mathrm{~cm}$ plate for incubation at $37.5^{\circ} \mathrm{C}$, $5 \% \mathrm{CO}_{2}$. The medium was replaced every $2-3$ days to remove non-adherent cells and adherent cells were passaged with $0.25 \%$ trypsin-EDTA (Sigma) just prior to reaching confluency. This resulted in the cells being passaged every 3-7 days at a seeding density of approximately 10,000 cells $/ \mathrm{cm}^{2}$. For IFN- $\gamma$ treatment, cells were plated in normal growth media and allowed to attach overnight before the addition of $100 \mathrm{ng} / \mathrm{ml}$ equine IFN- $\gamma$ (R\&D Systems, Abingdon, UK) for $72 \mathrm{~h}$.

\section{MSC differentiation}

For adipogenic differentiation confluent cells were treated with fat induction media (DMEM supplemented with $10 \%$ fetal calf serum, 15\% rabbit serum (all from Invitrogen), $10 \mu \mathrm{g} / \mathrm{ml}$ insulin, $1 \mu \mathrm{M}$ dexamethasone, $0.02 \mathrm{mM}$ indomethacin, and $0.5 \mathrm{mM} 3$-isobutyl-1-methylxanthine [all from Sigma]) for 3 days followed by 3 days in fat maintenance media (DMEM supplemented with 10\% fetal calf serum and $10 \mu \mathrm{g} / \mathrm{ml}$ insulin). This was repeated for 3 cycles before staining with Oil red $\mathrm{O}$ was carried out. For chondrogenic differentiation confluent cells were treated with cartilage induction media (DMEM supplemented with $10 \%$ fetal calf serum, $2 \mathrm{mM}$ L-glutamine, $100 \mathrm{U} / \mathrm{ml}$ penicillin, $100 \mu \mathrm{g} / \mathrm{ml}$ streptomycin, $1 \times 10^{-7} \mathrm{M}$ dexamethasone [Sigma]) and $10 \mathrm{ng} / \mathrm{ml}$ TGF- $\beta 1$ (Peprotech, London, UK) for 3 weeks before staining with alcian blue $\mathrm{pH}$ 1.0. For osteogenic differentiation a confluent monolayer of cells was cultured for 3 weeks in osteogenic induction media (DMEM supplemented with 10\% fetal calf serum, $2 \mathrm{mM}$ L-glutamine, $100 \mathrm{U} / \mathrm{ml}$ penicillin, $100 \mu \mathrm{g} / \mathrm{ml}$ streptomycin, $10 \mathrm{mM} \beta$-glycerophosphate (Sigma), $10 \mathrm{nM}$ dexamethasone and $0.1 \mathrm{mM}$ ascorbic acid (Sigma) before staining with Alizarin red $\mathrm{S}$.

\section{Immunocytochemistry}

Cells to be used in immunocytochemistry were grown in 24 well plates on gelatin-coated coverslips (Sigma). The cells were fixed in 3\% paraformaldehyde in phosphate buffered saline (PBS) for $20 \mathrm{~min}$ at room temperature and permeabilized for $1 \mathrm{~h}$ with $0.1 \%$ triton-X-100 at room temperature. Primary antibody incubations were carried out for $1 \mathrm{~h}$ at room temperature before using the peroxidase $\mathrm{ABC}$ detection system (Vector Laboratories, Peterborough, UK) and DAB substrate (DakoCytomation, Cambridgeshire, UK). The antibodies used included: rabbit anti-Oct-4 (1:100), rabbit anti-collagen type III (1:100) and rabbit anti-CD79 $\alpha$ (neat) (all from Abcam, Cambridge, UK), mouse anti-SSEA-1 (1:100), rat anti-SSEA-3 (1:100), mouse anti-SSEA-4 (1:100) and mouse anti-collagen type II (1:100) (all from Chemicon, Hampshire, UK), mouse anti-TRA-1-60 (1:500) and mouse anti-TRA-1-81 (1:500) (kindly provided by Professor Peter Andrews, University of Sheffield, UK), mouse anti-MHC class I (1:200), mouse anti-MHC class II (1:200) and mouse anti-CD44 (1:100) (all from VMRD, Washington, USA), 
mouse anti-CD90 (1:50) and mouse anti-CD14 (1:100) (both from BD pharmingen, San Diego, CA, USA), mouse anti-CD29 (1:40) (Beckman Coulter, Buckinghamshire, UK), mouse anti-collagen type I (1:10) (Sigma) and rabbit anti-collagen type IX/XI (1:200) (Calbiochem, San Diego, CA, USA). Nuclei were counter stained with hematoxylin prior to mounting. Alkaline phosphatase activity was detected using the Chemicon detection kit according to the manufacturer's protocol. All experiments were performed in triplicate on three independent lines of MS cells from each tissue source between passage 2 and 12. Negative controls were carried out with isotype-matched sham primary antibodies.

\section{Western blot analysis}

Western blot was performed using mouse anti-collagen type II (Chemicon) antibody at a dilution of 1:2000 on chondrocytes at P0 and skin fibroblasts at P3 isolated from cartilage and skin from an adult horse at post mortem. Whole cell extract was isolated by three rounds of freeze-thaw in extraction buffer ( $5 \mathrm{mM}$ EDTA, $5 \mathrm{M} \mathrm{NaCl}$, 0.5 M Hepes pH7.9, $100 \mathrm{mM}$ PMSF) and supernatants were collected by centrifugation. $15 \mu \mathrm{g}$ of denatured protein was run on a 6\% SDS-polyacrylamide gel and transferred to a PDVF membrane. Immunoreactivity was detected using the ECL plus detection system (Amersham, Buckinghamshire, UK). Mouse anti- $\beta$ actin antibody (Abcam) was used as a positive control.

\section{Results \\ Morphological characteristics of horse MS cells and collagen expression}

The isolated MS cells showed typical spindle morphology and resembled those previously reported in the literature (Figure 1). The MS cells could be grown in continuous culture for approximately 14 weeks, being passaged once or twice a week, before they began to senesce and die out. However, MS cells could be cryopreserved and displayed high viability after thawing. The MS cells could also be differentiated into fat, cartilage and bone, demonstrating their multipotency (see Figure 1). Immunocytochemical analyses
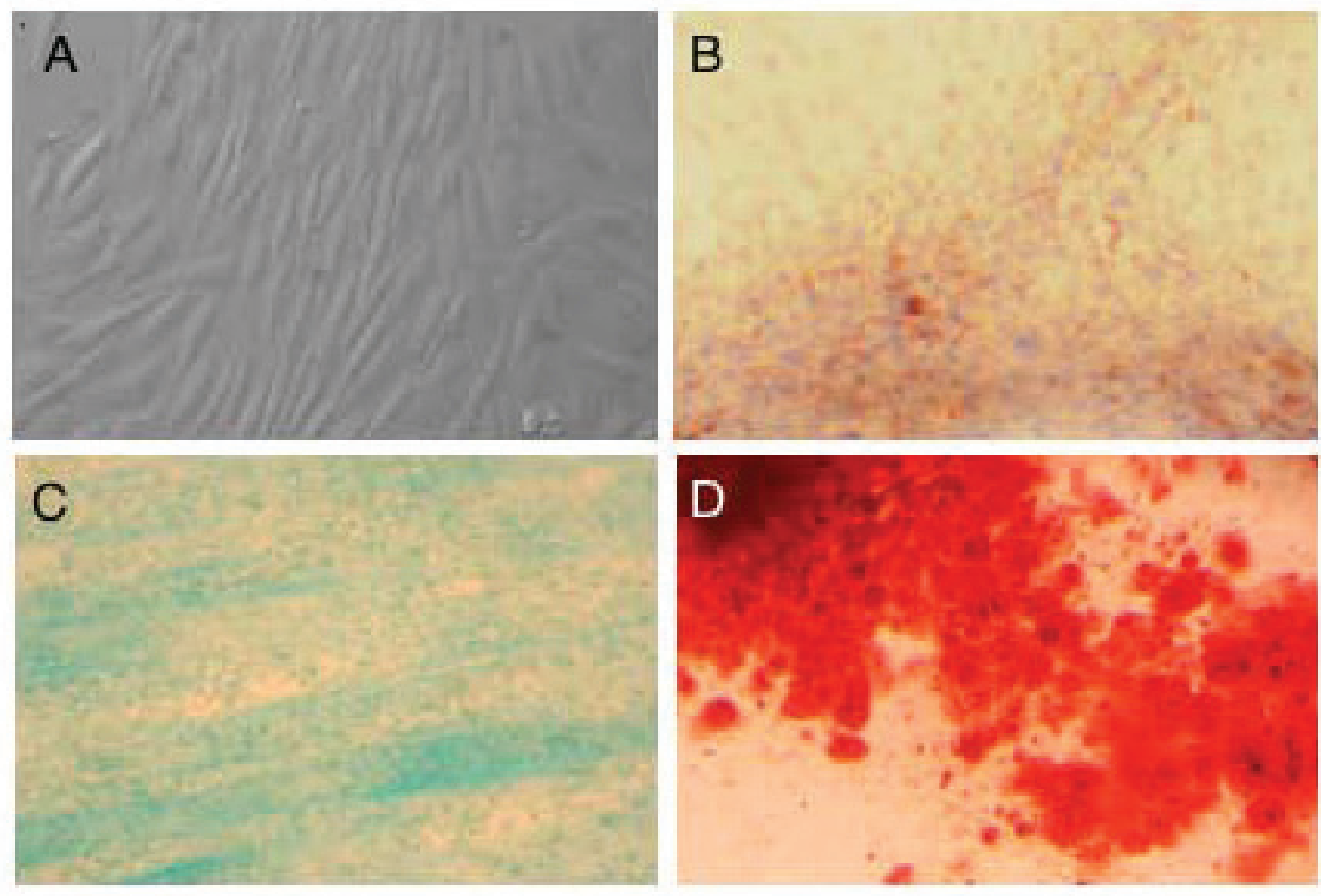

Figure I A representative example of multi-lineage differentiation of horse MS cells. (A) Phase contrast image of undifferentiated horse MS cells (magnification $\times 400$ ). (B) Oil red $\mathrm{O}$ staining of lipid droplets following adipogenic differentiation. (C) Alcian blue staining following cartilage differentiation. (D) Alizarin red S staining following bone differentiation (B-D magnification $\times 100)$. 
of the MS cells revealed that both collagen type I and type III are expressed (Figure $2 \mathrm{a}$ and $\mathrm{b}$ ). In addition, collagen type II and type IX/XI, usually associated with cartilage, are also expressed in culture expanded horse MS cells (Figure 2c and d). As collagen type II was thought to be specific for cartilage, western blot analysis was carried out to confirm the specificity of the antibody (Figure 3). A single band of approximately $190 \mathrm{kDa}$ was produced in the lane containing protein from chondrocytes but not skin fibroblasts.

\section{Expression of ES cell marker proteins in horse MS cells}

The expression of ES cell proteins was examined in the MS cells. These proteins had all been previously shown to be expressed in horse ES-like cells (Guest and Allen 2007) and included Oct4, SSEA-1, -3, -4, TRA-1-60, TRA-1-81, and alkaline phosphatase activity. Of these, only alkaline phosphatase was expressed in the horse MS cells (Figure 4). However, although the majority of MS cells isolated from bone marrow expressed alkaline phosphatase activity (Figure 4ai), it was expressed in only a minority of the MS cells isolated from umbilical cord blood (Figure 4aii). No protein was detected for any of the other ES cell markers by immunocytochemical analysis.
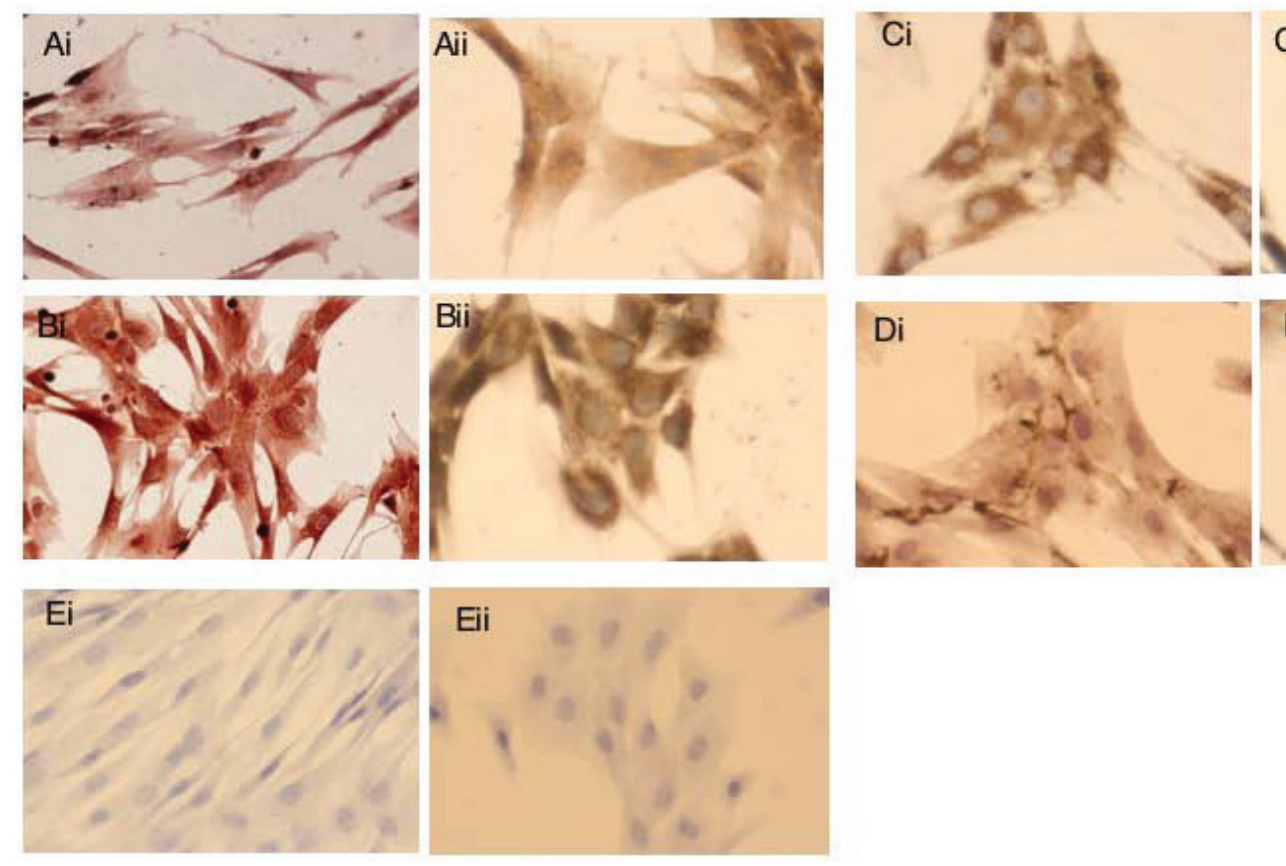

\section{Expression of cluster of differentiation antigens in horse MS cells}

A selection of CD antigens, which are used to identify human MS cells, were studied. All of the antibodies were tested on peripheral blood mononuclear cells for their ability to detect horse antigens (data not shown). The horse MS cells expressed CD29, CD44 and CD90 antigens (Figures 5a-c), but did not express detectable levels of CD14 or CD79 $\alpha$ antigens (Figures 5d, 5e).

\section{Expression of $\mathrm{MHC}$ antigens by horse bone marrow-derived MS cells}

The horse MS cells were found to express MHC class I antigens but not MHC class II antigens under normal culture conditions (Figures 6a, 6c). However, MS cells from the unbilical cord blood showed much fainter staining for MHC I (Figure 6aii) than the MS cells isolated from adult bone marrow (Figure 6ai). Treatment with $100 \mathrm{ng} / \mathrm{ml}$ of IFN- $\gamma$ for $72 \mathrm{~h}$ resulted in an increase in the expression of MHC class I antigens in MS cells isolated from both sources (Figure 6b). However, although INF- $\gamma$ treatment led to an induction of MHC class II antigens in MS cells isolated from adult bone marrow (Figure 6di) no induction of class II antigens was visible in MS cells isolated from umbilical cord blood (Figure 6dii).

Figure 2 Immunocytochemical analysis of collagen expression in horse MS cells. Positive cytoplasmic staining (brown) is observed in bone marrow- (i) and cord blood (ii)-derived MS cells with: (A) collagen type I, (B) type III, (C) type II, and (D) type IXIXI. (E) Representative negative control carried out with an isotype matched sham primary antibody. Nuclei were stained with haematoxylin (blue). Magnification $\times 400$. 
1

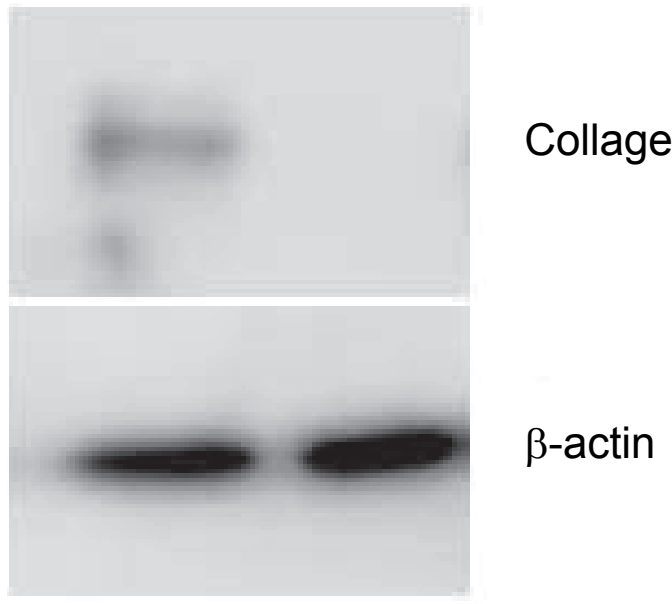

Figure 3 Western blot analysis using the collagen type II antibody. A single band of approximately $190 \mathrm{kDa}$ was produced in the lane containing protein isolated from chondrocytes $(\mathrm{I})$ but no band was produced in the lane containing protein from skin fibroblasts (2) An antibody to $\beta$-actin produced bands of similar intensity at approximately $45 \mathrm{kDa}$ in both lanes.

\section{Discussion}

In the present study we have examined the expression profile of a selection of markers in equine bone marrow and umbilical cord blood-derived MS cells. In order to gauge the biological activity of the markers, we chose to examine the presence of the protein rather than measuring mRNA levels which may or may not be translated. As we wished to identify whether markers were homogeneous throughout the cell population of MS cells or present heterogeneously, immunocytochemistry was preferred over other methods such as western blots. Therefore, to determine a marker profile for horse MS cells, immunocytochemistry was carried out for all proteins except alkaline phosphatase, which was visualized using a kit to detect the active enzyme.

Previously it has been shown that collagen type I protein is expressed in undifferentiated horse bone marrow-derived MS cells and that a change to collagen type II occurs upon differentiation to cartilage (Fortier et al 1998). A similar shift from collagen type I to II during cartilage differentiation has also been reported at the mRNA level (Koerner et al 2006). However, no studies had previously examined the expression of collagen type III in horse MS cells, despite its reported expression in rat bone marrow stromal cells (Beresford et al 1992) and human MS cells derived from the Wharton's jelly of the umbilical cord blood (Wang et al 2004) and amniotic fluid (Kim et al 2007). In the present study we found that collagen type III also expressed the horse bone marrow-derived MS cells.

Surprisingly, we were also able to detect collagen type II and type IX/XI, which are usually associated with cartilage, in the undifferentiated horse MS cells, despite no positive staining being observed with alcian blue, suggesting spontaneous differentiation to mature cartilage had not taken place. This is in contrast to the study by Fortier and colleagues (1998) where no collagen type II was detected prior to cartilage differentiation. However, that study used cells at passage 1 after only 11 days in culture. The present study used cells between passages 2 and 10 for the analysis of collagen expression. This longer time frame may have allowed more enrichment for dividing MS cells. The study by Fortier and colleagues (1998) also did not utilize a Ficoll or Histopaque gradient in the isolation of their MS cells. In the present study the mononuclear cells were collected following the centrifugation of whole blood over a histopaque gradient. The different isolation methods could be responsible for the observed differences in collagen type II expression. However, in another study (Worster et al 2000), some immunoreactivity to collagen II was observed in the control cells and although mRNA levels of collagen II increased during chondrogenic differentiation induced with TGF- $\beta$, collagen II was expressed prior to differentiation. Koener and colleagues (2006) also found some collagen II mRNA expression in their undifferentiated monolayer cultures although expression increased dramatically upon induction of differentiation. It is possible that some cross reactivity occurs between the different collagen antibodies. However, all of the antibodies used produced differential staining patterns on sectioned horse cartilage tissue, as expected from observations in human cartilage (Roberts et al 2003) and western blot analysis with the collagen type II antibody produced a single band for protein produced from chondrocytes but not adult skin fibroblasts. In many reports on equine MS cells, few studies have examined the presence of collagen II protein in undifferentiated cells and few studies have presented the absolute data on gene expression, instead presenting a ratio of expression of collagen type I to type II during differentiation. The conflicting data generated in this report highlights the need for different laboratories to examine the expression of proteins in their putative MS cells in order to identify the key, common genes that can be used in the identification of horse MS cells.

The expression of ES cell markers was studied in the horse MS cells as some reports have shown the expression of subsets of these genes in MS cells from mouse and 

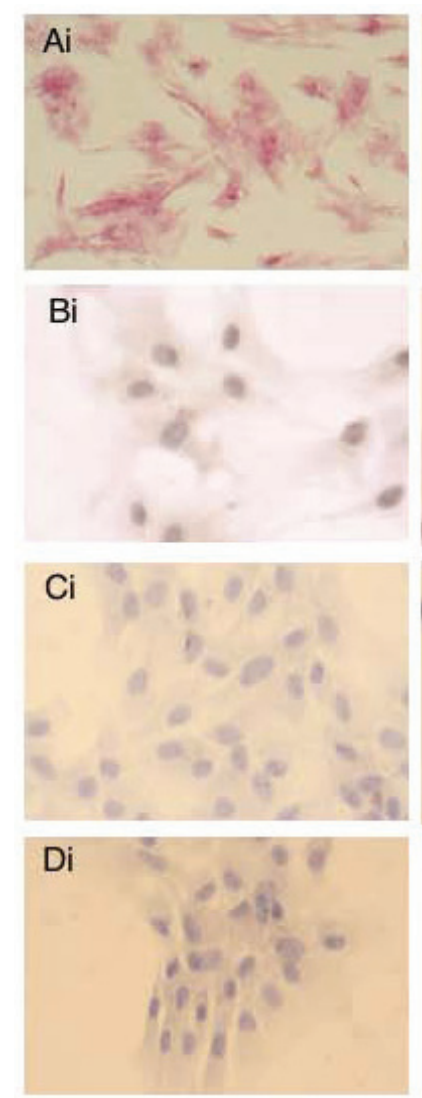
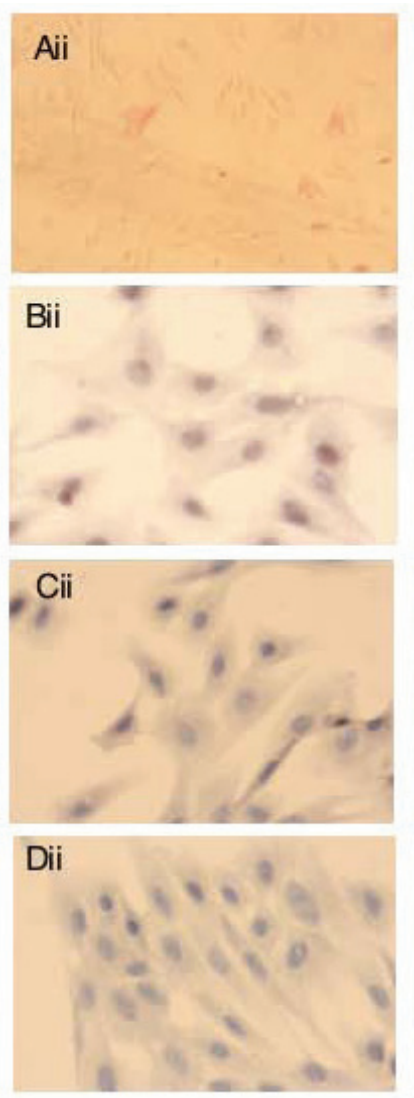
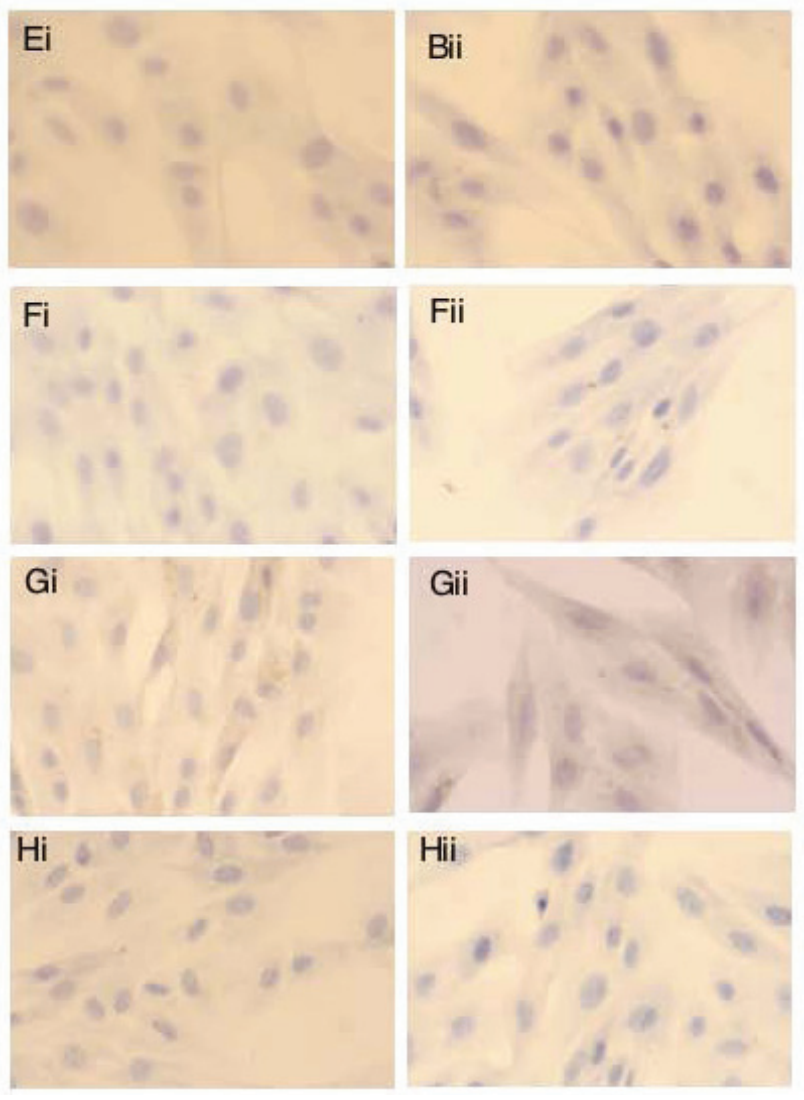

Figure 4 Staining horse MS cells derived from bone marrow (i) and cord blood (ii) for ES cell associated markers. (A) Positive staining (pink) for alkaline phosphatase activity (magnification $\times 100$ ). No staining (brown) was detected for Oct-4 (B), TRA-I-60 (C), TRA-I-8I (D), SSEA-3 (E), SSEA-4 (F) and SSEA-I (G) as compared to a negative control $(\mathbf{H})$. Nuclei were stained with haematoxylin (blue). Magnification $\times 400$.
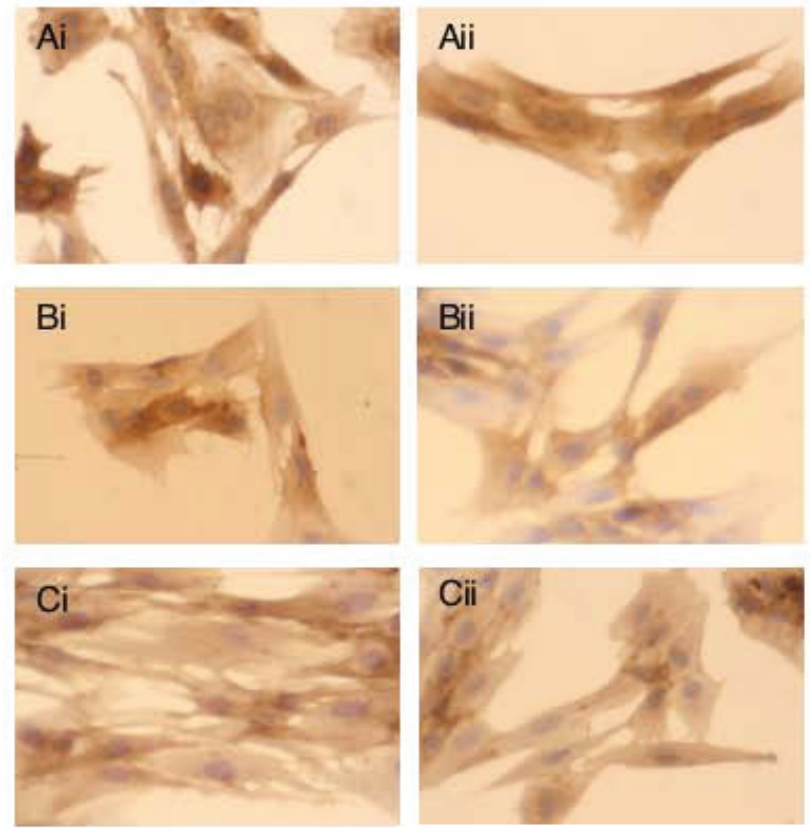
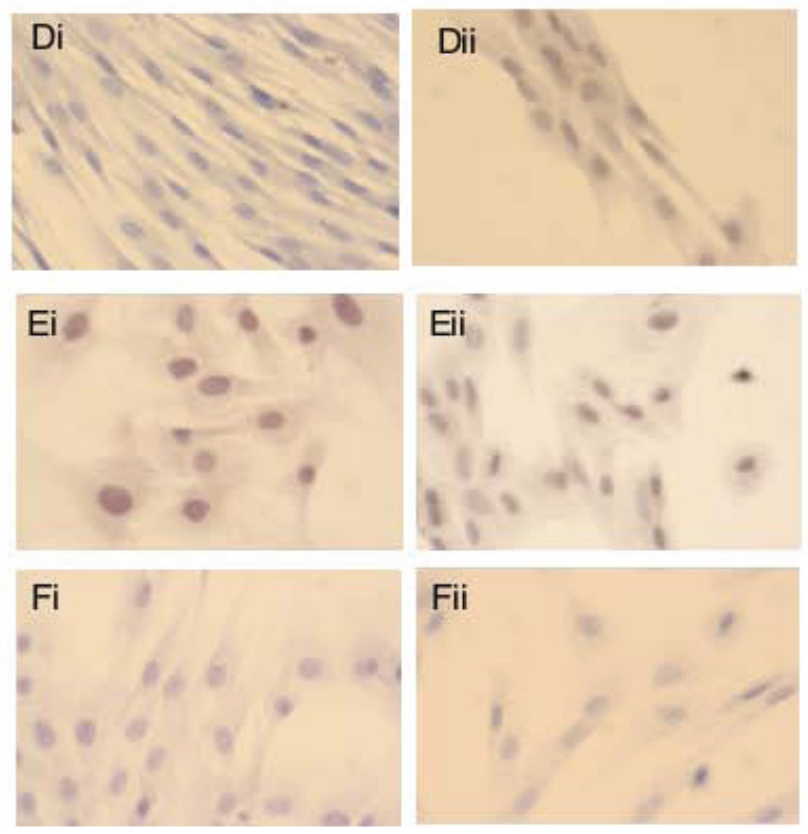

Figure 5 Immunocytochemical analysis of cluster of differentiation antigens in horse MS cells derived from bone marrow (i) and umbilical cord blood (ii). Positive staining (brown) was observed for CD29 (A), CD44 (B), and CD90 (C). No staining was observed for CDI4 (D) or CD79 $\alpha$ (E) as compared to a negative control (F). Nuclei were stained with hematoxylin (blue). Magnification $\times 400$. 


\section{Control}

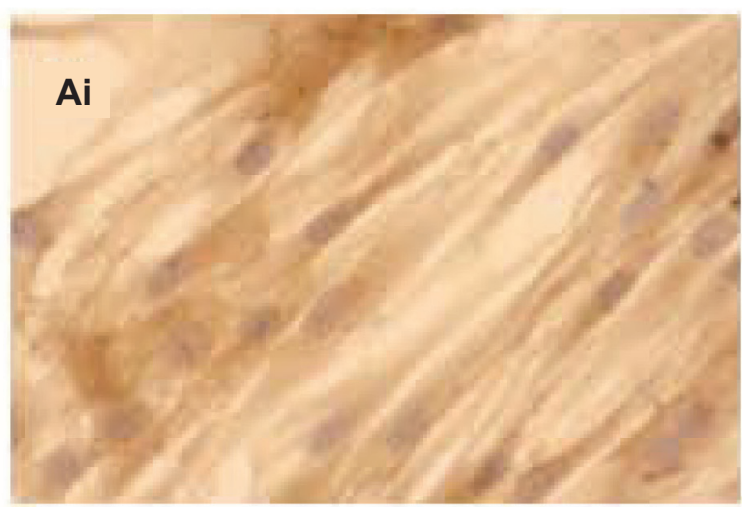

MHC I
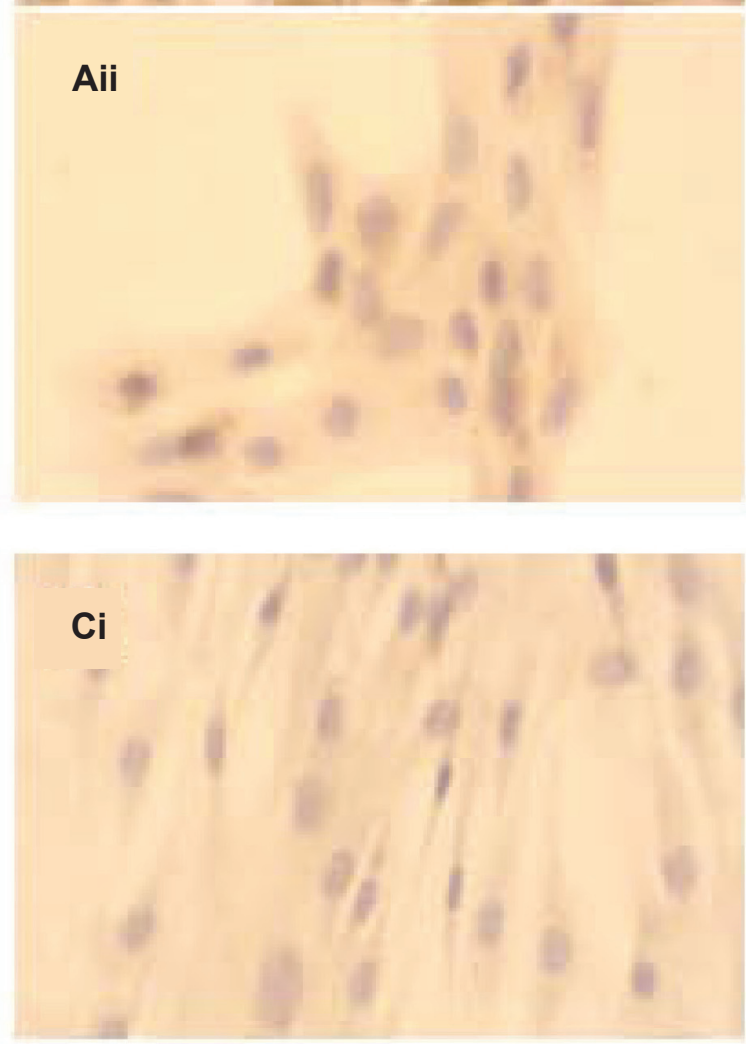

MHC II

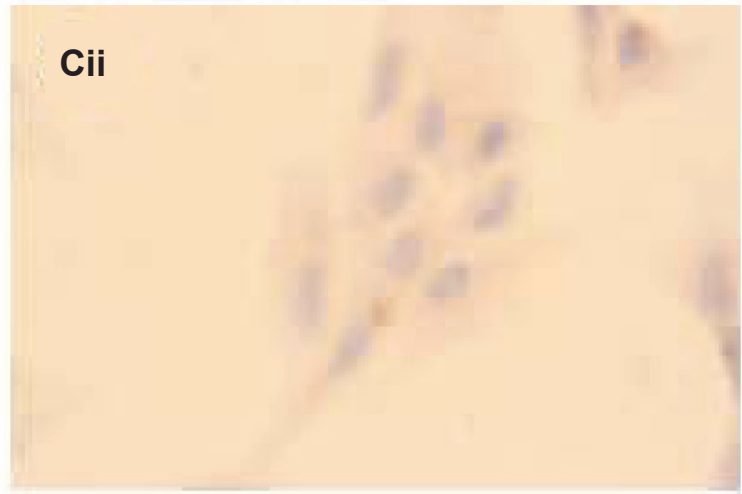

$100 \mathrm{ng} / \mathrm{ml} \mathrm{IFN- \gamma}$
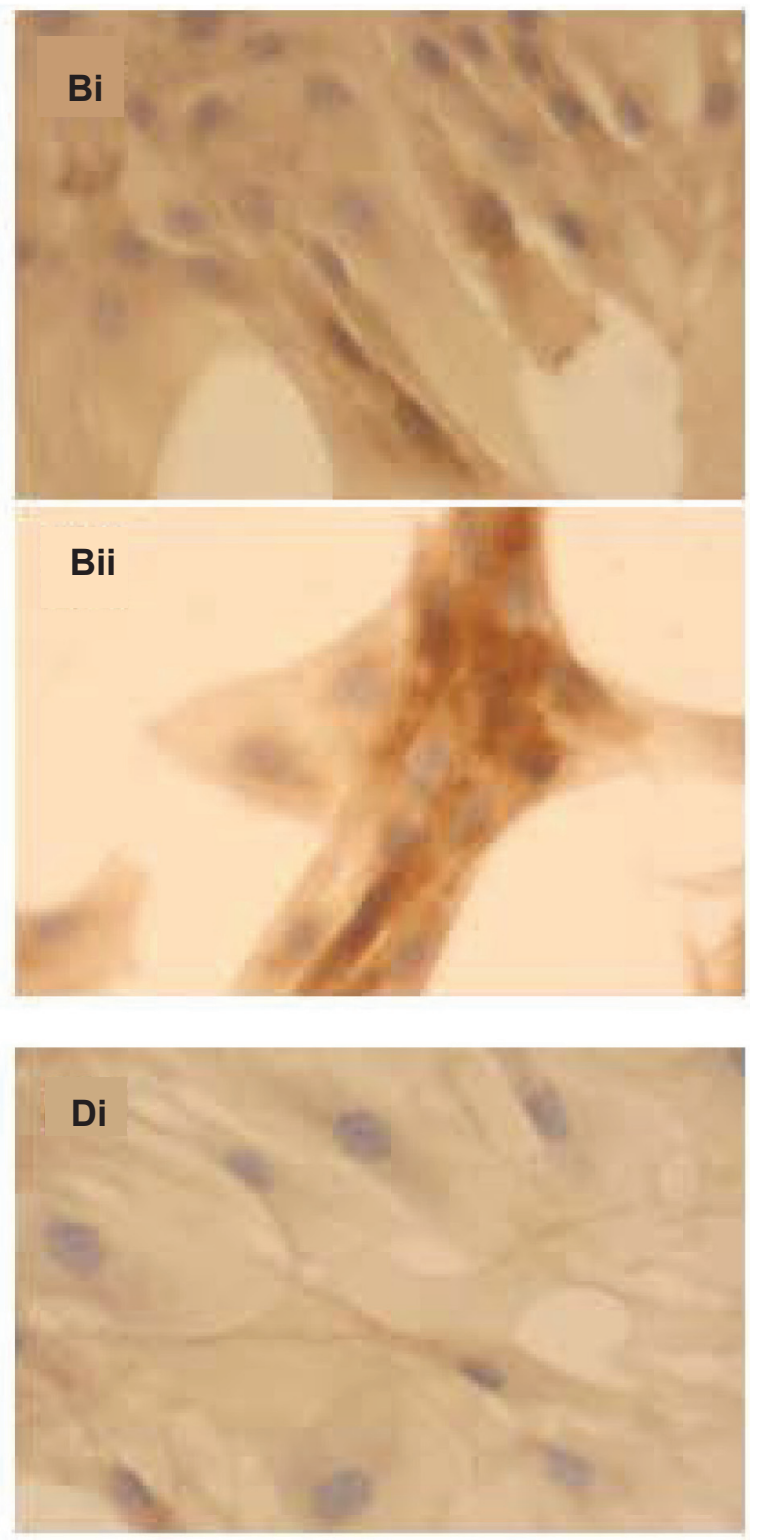

Dii

Figure 6 MHC expression in horse MS cells. Control MS cells stain positively (brown) for class I antigens (A) but bone marrow-derived cells (Ai) show much stronger staining than umbilical cord blood-derived cells (Aii). Control MS cells from both bone marrow (Ci) and umbilical cord blood (Cii) show no staining for class II antigens. Treatment with $100 \mathrm{ng} / \mathrm{ml} \mathrm{IFN-} \gamma$ for $72 \mathrm{~h}$ increases expression of class I antigens in bone marrow- (Bi) and umbilical cord blood (Bii)-derived MS cells but only induces expression of class II antigens in MS cells derived from bone marrow (D). Nuclei were stained with hematoxylin (blue). Magnification $\times 400$. 
human (De Coppi et al 2007; Gang et al 2007; Kim et al 2007). Horse MS cells isolated from umbilical cord blood have previously been reported to express Oct-4, SSEA-1, TRA-1-60, and TRA-1-81 as well as alkaline phosphatase activity and minor amounts of SSEA-4 (Reed and Johnson 2008). This report also found expression of Oct-4, TRA-1-60, and TRA-1-81 in adult horse MS cells derived from adipose tissue. However, these cells did not express SSEA-1 and SSEA-4, which the authors conclude, may therefore be genes more closely associated with ES cells. In fact, recent work has shown that expression of SSEA-3 and -4 in human ES cells are not essential for maintaining pluripotency despite their expression in undifferentiated cells and loss of expression during differentiation (Brimble et al 2007). Conflicting data exists on the expression of SSEA-4 in MS cells, with some studies reporting that it is expressed (Gang et al 2007) but others finding no evidence of its expression (Cheng et al 2003; Wagner et al 2005). In the present study, only alkaline phosphatase was expressed in the horse MS cells with expression in the majority of bone marrow-derived cells but only in a minority of umbilical cord blood-derived cells. This is in support of previous data in the horse that has shown alkaline phosphatase activity in bone marrow-derived and, to a lesser extent, in adipose tissuederived MS cells (Vidal et al 2007). The conflicting results on the expression of ES cell proteins in the umbilical cord blood-derived cells may reflect differences in the isolation methods used. In the present study whole blood was passed through a Histopaque gradient whereas in the previous report samples were first incubated with a progenitor enrichment cocktail (Reed and Johnson 2008).

Study of the expression of CD antigens demonstrated that the horse MS cells were similar to human MS cells, with positive staining observed for CD44, CD90, and CD29 and no staining observed for CD14 and CD79 $\alpha$. Although a broader range of $\mathrm{CD}$ antigens have been studied in human MS cells, we were restricted in the present report by the availability of antibodies that would recognize horse antigens.

Human MS cells have been shown to express MHC class I antigens but not class II antigens (Dominici et al 2006). In the present study we found that, under normal culture conditions, horse MS cells also express MHC class I but not class II antigens, although the levels of class I were much lower in MS cells isolated from umbilical cord blood than they were in those isolated from adult bone marrow. Furthermore, we found that although MHC II expression was induced by the culture of the bone marrow-derived MS cells

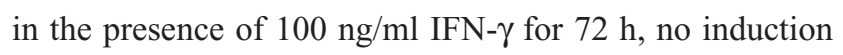

was observed in umbilical cord blood-derived MS cells. This data suggests that MS cells isolated at birth from the cord blood are less immunologically established than their adult counterparts. However, in vitro studies on human bone marrow-derived MS cells have shown that even following IFN- $\gamma$ treatment to induce MHC II expression no proliferative responses occur in alloreactive lymphocytes (Le Blanc et al 2003) and it appears that both horse (Guest et al 2008) and human (Horwitz et al 1999) bone marrow-derived MS cells can be used in allogeneic transplants without initiating an immune response from the host.

\section{Summary}

Taken together this data shows that bone marrow and umbilical cord blood-derived horse MS cells closely resemble human MS cells in terms of their expression of marker genes. This information can now be used to make comparisons between horse MS cells isolated from different laboratories and other tissue sources, for example adipose tissue, to identify markers that can be used as common standards in the identification of horse MS cells.

\section{Acknowledgments}

This work was kindly funded by the Horserace Betting Levy Board and the Childwick Trust. The authors would like to thank Deborah Willis and Lorraine Palmer for their assistance with the collection of umbilical cord blood samples. DJ Guest worked on concept and design, collection of data, data analysis and interpretation, manuscript writing; JC Ousey and MRW Smith collected study material. The authors report no conflicts of interest in this work.

\section{References}

Arnhold SJ, Goletz I, Klein H, et al. 2007. Isolation and characterisation of bone marrow-derived equine mesenchymal stem cells. Am J Vet Res, 68:1095-105.

Beresford JN, Bennett JH, Devlin C, et al. 1992. Evidence for an inverse relationship between the differentiation of adipocytic and osteogenic cells in rat marrow stromal cell cultures. $J$ Cell Sci, 102:341-51.

Bosch P, Pratt SL, Stice SL. 2006. Isolation, characterization, gene modification and nuclear reprogramming of porcine mesenchymal stem cells. Biol Reprod, 74:46-57.

Brimble SN, Sherrer ES, Uhl EW, et al. 2007. The cell surface glycosphingolipids SSEA-3 and SSEA-4 are not essential for human ESC pluripotency. Stem Cells, 25:54-62.

Chang Y-J, Tseng C-P, Hsu L-F, et al. 2006. Characterisation of two populations of mesenchymal progenitor cells in umbilical cord blood. Cell Biol Int, 30:495-9.

Cheng L, Hammond H, Ye Z, et al. 2003. Human adult marrow cells support prolonged expansion of human embryonic stem cells in culture. Stem Cells, 21:131-42.

De Coppi P, Bartsch G, Siddiqui MM, et al. 2007. Isolation of amniotic stem cell lines with potential for therapy. Nat Biotech, 25:100-6. 
Dominici M, Le Blanc K, Mueller I, et al. 2006. Minimal criteria for defining multipotent mesenchymal stromal cells. The International Society for Cellular Therapy position statement. Cytotherapy, 8:315-7.

Fortier LA, Nixon AJ, Williams J, et al. 1998. Isolation and chondrocytic differentiation of equine bone marrow-derived mesenchymal stem cells. Am J Vet Res, 59:1182-7.

Gang EJ, Bosnakovski D, Figueiredo CA, et al. 2007. SSEA-4 identifies mesenchymal stem cells from bone marrow. Blood, 109:1743-51.

Guest DJ, Allen WR. 2007. Expression of cell surface antigens and embryonic stem cell pluripotency genes in equine blastocysts. Stem Cells Dev, 16:789-95.

Guest DJ, Smith MRW, Allen WR. 2008. Monitoring the fate of autologous and allogeneic mesenchymal progenitor cells injected into the superficial digital flexor tendon of horses: preliminary study. Equine Vet $J, 40: 178-81$.

Hegewald A, Ringe J, Bartel J, et al. 2004. Hyaluronic acid and autologous synovial fluid induce chondrogenic differentiation of equine mesenchymal stem cells: a preliminary study. Tissue Cell, 36:431-8.

Horwitz EM, Prockop DJ, Fitzpatrick LA, et al. 1999. Transplantability and therapeutic effects of bone marrow-derived mesenchymal cells in children with osteogenesis imperfecta. Nat Med, 5:309-13.

Hoynowski SM, Fry MM, Gardner BM, et al. 2007. Characterisation and differentiation of equine umbilical cord-derived matrix cells. Biochem Biophys Res Commun, 362:347-53.

Kim J, Lee Y, Kim H, et al. 2007. Human amniotic fluid-derived stem cells have characteristics of multipotent stem cells. Cell Prolif, 40:75-90.

Koch TG, Heerkens T, Thomsen PD, et al. 2007. Isolation of mesenchymal stem cells from equine umbilical cord blood. $B M C$ Biotechnol, 7:26.

Koerner J, Nesic D, Romero JD, et al. 2006. Equine peripheral blood-derived progenitors in comparison to bone marrow-derived mesenchymal stem cells. Stem Cells, 24:1613-19.

Le Blanc K, Tammik C, Rosendahl K, et al. 2003. HLA expression and immunologic properties of differentiated and undifferentiated mesenchymal stem cells. Exper Hematol, 31:890-6.
Pereira RF, Halford KW, O'Hara MD, et al. 1995. Cultured adherent cells from marrow can serve as long-lasting precursor cells for bone, cartilage, and lung in irradiated mice. PNAS, 92:4857-61.

Pittenger MF, Mackay AM, Beck SC, et al. 1999. Multilineage potential of adult human mesenchymal stem cells. Science, 284:143-7.

Prockop DJ. 1997. Marrow stromal cells as stem cells for nonhematopoietic tissues. Science, 276:71-4.

Reed SA, Johnson SE. 2008. Equine umbilical cord blood contains a population of stem cells that express Oct 4 and differentiate into mesodermal and endodermal cell types. J Cell Physiol, 215:329-36.

Roberts S, McCall IW, Darby AJ, et al. 2003. Autologous chondrocyte implantation for cartilage repair: monitoring its success by magnetic resonance imaging and histology. Arthritis Res Ther, 5:R60-R73.

Smith RKW, Korda M, Blunn GW, et al. 2003. Isolation and implantation of autologous equine mesenchymal stem cells from bone marrow into the superficial digital flexor tendon as a potential novel treatment. Equine Vet J, 35:99-102.

Vidal MA, Kilroy GE, Johnson JR, et al. 2006. Cell growth characteristics and differentiation frequency of adherent equine bone marrow-derived mesenchymal stromal cells: Adipogenic and osteogenic capacity. Vet Surg, 35:601-10.

Vidal MA, Kilroy GE, Lopez MJ, et al. 2007. Characterization of equine adipose tissue-derived stromal cells: Adipogenic and osteogenic capacity and comparison with bone marrow-derived mesenchymal stromal cells. Vet Surg, 36:613-22.

Wagner W, Wein F, Seckinger A, et al. 2005. Comparative characteristics of mesenchymal stem cells from human bone marrow, adipose tissue, and umbilical cord blood. Exper Hematol, 33:1402-16.

Wang H-S, Hung S-C, Peng S-T, et al. 2004. Mesenchymal stem cells in the Wharton's Jelly of the human umbilical cord. Stem Cells, 22:1330-7.

Wilke MM, Nydam DV, Nixon AJ. 2007. Enhanced early chondrogenesis in articular defects following arthroscopic mesenchymal stem cell implantation in an equine model. J Orthop Res, 25:913-25.

Worster AA, Nixon AJ, Brent D, et al. 2000. Effect of transforming growth factor $\beta 1$ on chrondrogenic differentiation of cultured equine mesenchymal stem cells. AJVR, 61:1003-10. 
